\title{
IMF stabilisation and structural adjustment in sub-Saharan Africa: are they technically compatible?
}

\author{
Reginald Green
}

The International Monetary Fund is often charged with imposing austerity. This is a misconception... the austerity born of adjustment must be compared with the alternatives.

J. de Laroisiere, Managing Director, IMF, 1984

The crisis in Africa in recent years is overwhelmingly the product of external shocks . . . Without the heavy post- 1978 blows or, given those blows, with adequate international buffers against them, the majority of African economies would not be sliding backward as they are now doing ...

G. K. Helleiner, 1985

We must look our mistakes in the face if we are to avoid repeating them.

Rui Baltasar,

Finance Minister, Mozambique

Insufficient financing leads to unwarranted exchange rate depreciation, restriction or debt default.

Onno Ruding, Bank-Fund Interim Committee Chairman

\section{Prologue}

The likelihood of a uniform and unconditional answer to the title of this article applying to all sub-Saharan African economies is negligible. Botswana over 198283 operated an IMF-type stabilisation strategy albeit without using any IMF resources or actually concluding a standby agreement. This was highly successful in reducing demand and imports as well as in shifting financing patterns to bolster reserves. Because exports recovered rapidly and the cuts came after a period of sustained increases in output, real wages and imports, the duration and cost of austerity were low (see Charles Harvey's article in this Bulletin). Over 1974-79 Rhodesia (as it then was) ran an IMF type stabilisation programme - for different reasons also without using Fund resources. This programme restored current account balance, held inflation below world levels and kept the recurrent budget more or less in balance. But because the external environment did not improve, GDP per capita, real consumption, real savings and investment fell year by year while the structure of production - which had changed rapidly over 1965-74 - ceased to adjust [Kadhani and Green, 1985]. Zambia's successive IMF programmes have at least endured and in that sense are more successful than the majority. But the current account has not been restored to balance, nor have trade arrears been reduced significantly or any base laid to restore real output without an immediate re-emergence of gross external imbalance, despite draconic cuts in real wages, government per capita spending and imports. As a result of success in the sense of continuity but failure to regain external balance, IMF debt service is now of the order of 25 per cent of export earnings. This is one of the main problems to be surmounted if external balance is to be achieved.

The diversity of result illustrated here is not surprising. The Botswana case is very near the classic model in which a short term macro-monetary stabilisation programme should work if undertaken promptly, except that the imbalances were caused by supply reduction not increased demand. The economy was strong. A record of high rates of real increase in both wages and public services for over a decade made cuts uncomfortable rather than crippling. With a high ratio of imports to GDP and negligible import control, cuts in imports were likely to follow fairly automatically from nominal demand restraint and to have low impact on real domestic production. The external shock (i.e. export quotas for diamonds which forced export cuts) could be expected to be - and was - self reversing.

The Rhodesian case is intermediate. The economy was fairly strong and the response to the 1973-74 changes in global economic conditions fairly prompt. But,

IDS Bulfetin. 1985. vol 16 no 3, Institute of Development Studies. Sussex 
because of a low ratio of imports to GDP and imports dominated by inputs into production and investment with few final consumer goods, import cuts imposed much larger cuts in domestic production. As the external economic environment did not recover, the only way to maintain external and internal balance was to reduce output and capacity utilisation: not once and for all but on a sinking equilibrium path.

Zambia - like Rhodesia in 1974 - was hit by the collapse of a metal boom. Its economy was already weakened by the costs of the Rhodesian rebellion, the rise in oil and grain prices and distortions in the production structure arising from its previous export boom (see Philip Daniel's article in this Bulletin). The negative impact of the shift in terms of trade on effective GDP and real government revenue was so large that even a relatively high initial import to GDP ratio did not give room for cuts adequate to restore either external or fiscal balance, and the cuts made caused a significant reduction in domestic output. As real metal prices never recovered, and import cuts eroded the export base, the structural position worsened if anything.

\section{IMF Resource Access and Adjustment: Necessary? Sufficient? Neither?}

What is more surprising are the questions the three cases raise in respect to using IMF resources. Botswana did not need to - although it could have done so, and given the brief duration of its imbalanced nine per cent loan over six years (the basic IMF terms) would not have created severe debt management problems.

Rhodesia, as a non-recognised entity, could not borrow from the IMF - although it probably would have had it been able to. Given the 1974-79 record, in retrospect it is hard to see that - say - $\$ 250 \mathrm{mn}$ would have done anything more than worsen the medium term external balance. As the IMF debt service/export ratio demonstrates, Zambia has found that short term, semi-commercial interest rate credit is not the road to structural adjustment, any more than are commercial arrears.

The IMF has always been quite clear in stating that it is not in the development business. In cases lasting longer or requiring more resources than the first credit tranche and Compensatory Finance Facility (to offset export declines) the question is whether the IMF is an appropriate source of interim finance at all for low and middle income SSA economies. Unless they can expect a natural recovery of import capacity from exports there is reason to suspect that the answer is no.

The argument may well not apply to countries with idle capacity and/or domestic oriented production susceptible to being shifted to exports if domestic demand falls - e.g. Italy, Turkey, Brazil. There, devaluation and demand cuts should lead to fairly rapid export increases and an approach to trade balance (including invisibles), even if at substantial cost. For countries whose exports are dominated by specific low price primary products with low income elasticity, it is unclear that devaluation and domestic demand cuts do much to restore balance [cf Helleiner 1984; Loxley 1984] except at the cost of a very high loss in domestic output, and perhaps also a falling equilibrium. Certainly the input supply and capital requirements needed to maintain existing export bases have at times fallen victim to IMF programmes, and the investment needed to build up new ones is even more vulnerable. It is also unlikely to produce substantial results inside the three-year life of an IMF drawing programme.

\section{Technical, Not Ideological}

This line of critique is not ideological but technical. In fact the ideological element in IMF-SSA relations is rather overstressed. The crux of the argument is: political survivability (as recently in the Sudan); the proper time frame for adjustment; the starting point in structural adjustment (i.e. real supply or monetary demand); the virtues of shock loading costs at the start versus phasing them parallel to benefits; and similar issues which are not usefully seen as having any clear relationship to ideology.

There are issues which can be defined as ultimately ideological, e.g. free versus managed markets, privatisation, income transfers and distribution. However, in practice most actual debates turn on degrees and balances not either/or choices, and are very often a mixing of ideological, technical and factual issues. The two most consistent strands of IMF policy prescription: that devaluation is a good all purpose medicine ${ }^{1}$ taken in large doses and that consumer subsidies are always highly undesirable, ${ }^{2}$ simply do not add up to any standard political,

\footnotetext{
There is one major, surprising exception in SSA. The IMF has not - so far as is known - pressed the CFA franc zone countries to devalue. As the CFA/French franc parity was set nearly 40 years ago at a rate overvaluing the (then) colonial franc; the French franc has not usually been viewed as undervalued; most CFA country inflation rates have been above that of France and the CFA economies have quite divergent structures, trends and degrees of external and fiscal imbalance, this exception is a rather intriguing one. So too is the ability - before 1979 and to a degree since - of many of these states to combine overvalued currencies and liberal import and capital transfer regulations with external balance and export growth.

2 SSA is a somewhat strange choice of location to give general priority to this theme. The region has by far the lowest ratio of consumer transfer payments in government expenditure in the world and in few cases consumer subsidies are a major cause of government recurrent budget deficits.
} 
political-economic or economic ideology. Certainly the IMF is prone to be sure it knows best, to generalise from a limited number of cases, to be selective in the use of data (especially when available data are fragmentary, conflicting and of doubtful accuracy) and rigid in presenting its case, not least in its occasional dialogues with friendly critics [see Killick ed. 1984]. That is in a real sense an ideology, but not what is normally meant by ideological controversy about IMF prescriptions, nor is it the main topic of this article.

\section{The IMF Model of Economic Imbalance and Its Cure}

The IMF operates on a relatively uniform set of assumptions about the causes of external imbalance and the structures and response patterns of economies. Some of these are fairly explicit, others are implicit in lending policies [see Williamson 1982], others emerge only from looking at a set of programmes or detailed discussion which arises in programme negotiations with IMF staff.

The basic assumptions of the IMF model can be summarised as follows:

1. the primary cause of external and internal imbalance is a major and usually sudden increase in the use of real resources;

2. demand reduction can restore balance by cutting back on recent personal (especially wage earner) and public (especially transfer payment) consumption while allowing rising real investment to take care of bolstering supply. Consequent falls in output will be low, brief and not in key areas of the economy;

3. room exists for rapid export expansion by reactivating capacity made idle by overvalued exchange rates and/or shifting capacity freed by reduced demand from the domestic to the export market;

4. higher import prices (from devaluation) combined with reduced market intervention/rationing of imports lead to lower import levels and to improved allocation of imports and production;

5. the economy is relatively flexible and internally integrated without major real gaps or sectoral fragmentation (in one sense this provides the basis for the two previous assumptions);

6. nominal price changes can be expected to lead to real relative price changes (externally and internally) and therefore to improve allocative efficiency while reducing demand. Apparently the assumption includes the view that falling nominal demand can be achieved and will choke off inflation;

7. reductions in demand and market intervention and new relative price ratios (including the exchange rate) should be carried out over a brief period to secure maximum shock effect toward rebalancing, with fairly modest subsequent steps to undo reversals caused by inflation;

8. restoration of balance and return to growth can be achieved in a relatively brief period - three years judging from the lending programme limit because of assumed flexibility and the ability to raise exports sharply. Therefore given the assumption that imbalance follows sharp increases in real resource use, temporary cutbacks from 'shock' adjustment phasing will not pose major problems, since they will soon be followed by renewed gains.

\section{SSA's Post-1979 Economic Malaise and the Model}

Whether these assumptions are or are not reasonably accurate, either in general or in specific cases, is not an ideological question but a mixed empirical/judgement one. A substantial body of writing [e.g. in Williamson 1983; Killick 1984; Dell Lawrence and Helleiner 1985] raises such questions in respect to most developing economies. However, the concern of the present article is narrower. In SSA the following would appear to be the case with respect to the IMF's assumptions:

1 . in a majority of cases the primary (and certainly the immediate) cause of imbalance was a fall in real resource availability triggered by an external shock (e.g. terms of trade, quantitative decline in the demand for exports, drought) or a war (civil or external). High rates of increase in real consumption before the sudden emergence of major imbalance are exceptions (e.g. Botswana, in the very short run but not over a five year perspective, Zimbabwe);

2. demand reductions, therefore, will not merely reverse recent increases but cut into basic levels of resource use. Because profits and foreign finance are typically low and falling, private investment is likely to be cut sharply. Cuts in government resource use large enough to restore recurrent balanced budgets will need to go much further than subsidies, because real revenue falls very fast with demand constraint and interest payments rise rapidly from both the stabilisation finance and the initial deficit. Consequential falls in domestic output are likely to be several times greater than imports cuts and - whether market or interventionist methods of constraint are used - import 


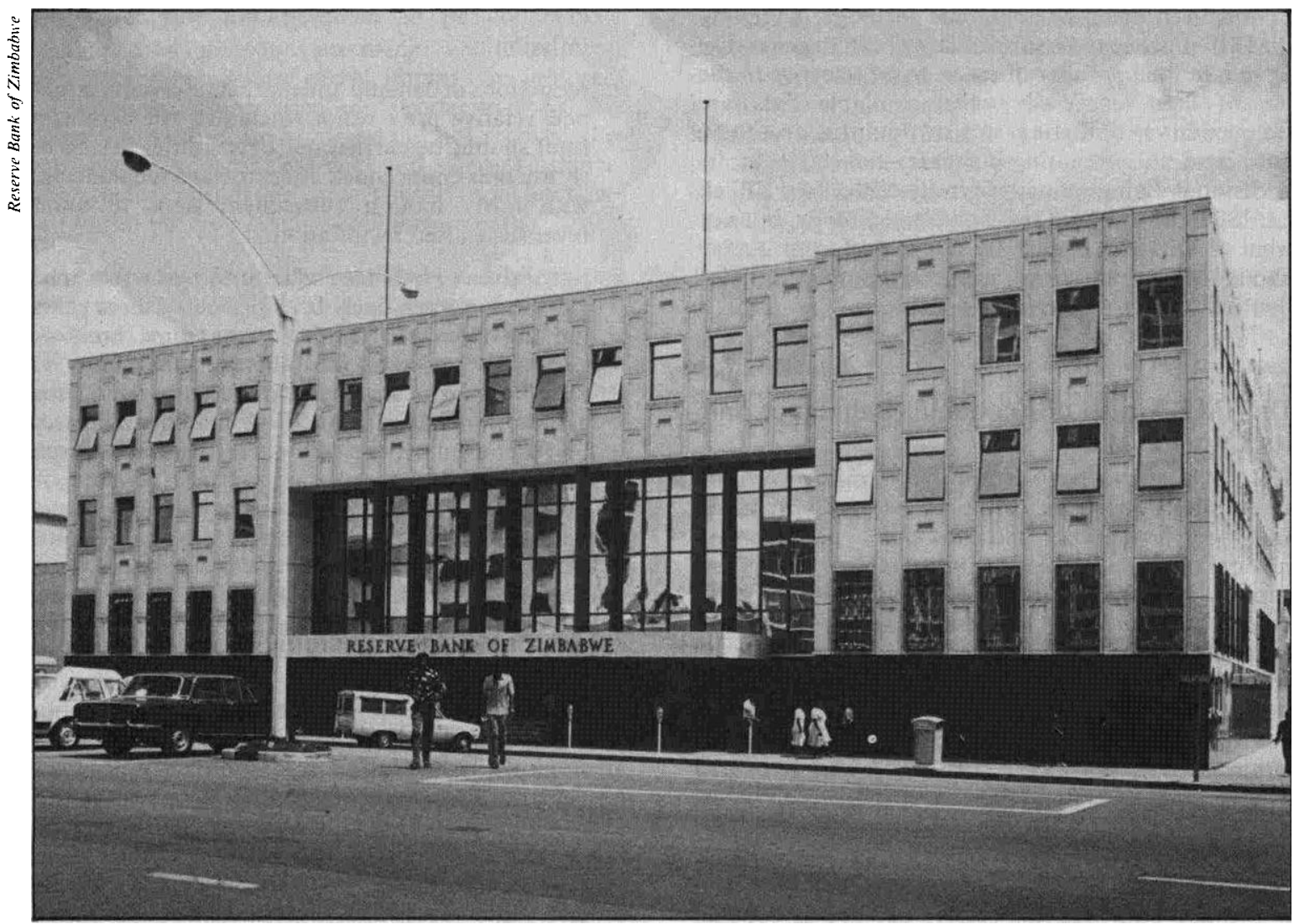

Imbalance triggered by external shocks.

cuts are unlikely to be concentrated on final consumption goods as opposed to operating, maintenance or investment inputs; ${ }^{3}$

3. little room exists for rapid export expansion. Physical constraints, often exacerbated by import cuts in stabilisation programmes both in agriculture and in related processing and transport, are one factor, and global (as well as domestic) price incentives are another. Scope for switching domestic production to export markets is usually limited (Zimbabwe's manufacturing sector is a partial exception) even if foreign exchange to maintain output is available. Many traditional exports are doubtful candidates for rapid increases in output for price elasticity reasons [see Martin Godfrey's article in this Bulletin] and new ones are either hard to identify or will require substantial

\footnotetext{
There are exceptions. Botswana's stabilisation programme's market force operated real import reduction did centre on consumer amenity goods. Tanzania's interventionist allocation of imports has virtually eliminated consumer goods other than grain, pharmaceuticals and the 15 to 20 per cent of petroleum products corresponding to non-business car use and household kerosine consumption.
}

amounts of time, finance and foreign exchange to develop;

4. in cases with a history of detailed import licensing, major liberalisation is inconsistent with reducing import levels because the true price elasticity is very low - especially for amenity consumer goods. Market incentives (i.e. quick, easy, relatively high profits) seem to result in liberalisation, ${ }^{4}$ shifting the balance of imports away from maintenance and production inputs toward consumer amenities. This is not necessarily an allocational improvement, as it is likely to maximise the cost of any import reduction and, indeed, to erode the future export base;

5. most SSA economies are fragile, with limited domestic integration and very substantial production, maintenance and investment input gaps which can be breached only by imports. In many

\footnotetext{
4i.e., this criticism might not apply to selective liberalisation of categories of goods useable only for production and maintenance or for specific producers, or classes of producers, imports of goods to be used in further production and/or capacity maintenance/ rehabilitation.
} 
cases import to GDP ratios have fallen not because of import substitution but because of sheer absence of foreign exchange leading to massive capacity underutilisation and undermaintenance;

6. nominal price changes tend to be overtaken rapidly by inflation especially when initial changes are large, partly because of cost plus pricing and partly because of physical constraints. The only exceptions appear to be reductions in real wages and salaries and effective grower prices for export or industrial crops. ${ }^{5}$ In general, sharp increases in nominal grower prices, in government or parastatal charges and in basic import prices (e.g. fuel, food) promote inflation rather than redistribution, or any alteration in the level or pattern of output;

7. rapid changes at the macro-monetary level tend to have both unexpected and undesired side effects (e.g. credit ceilings which block the use of available export production capacity, government budget cuts which immobilise extension personnel) and to generate cumulative inflationary forces which largely or wholly offset them in a brief period of time. Further, by front end loading the costs they create problems of acceptance, morale and programme survivability which affect likely stabilisation and production outcomes even if they are social and political rather than narrowly economic. $^{6}$

8. given the initial (and unreversed) loss of command over the dominant role of real resources in most SSA cases of extreme imbalance, the rigidity of their economies and the poor prospects for high, sustained export growth, few can achieve a stable base for renewed growth within three years without sharp increases in net foreign exchange availability sust ained over three to seven years with limited and phased increases in their debt servicing burden.

Certain details of, or emphases within, this sketch are doubtless controversial. But it is by and large the pattern which emerges from a range of studies [IDS 1983; World Bank 1984; JDP 1985]. Even the World Bank's Accelerated Development Report [World Bank 1981] did not project any significant rise in real GDP per capita between 1979-1989 for low income African countries. Its 1984 Programme [World Bank 1984] projects typical 1990 levels of real output per capita well below those of 1980 and, implicitly at least, below those of 1970 in a substantial number of cases.

\footnotetext{
5 For domestic food or artisanal crops a low nominal (or real) official grower price leads primarily to more parallel marketing, not relative price shifts in favour of consumers and against growers.

6 e.g. wage earners do respond to economic incentives and disincentives. Sharp and unreversed real wage falls lead to cumulative productivity. morale and presence at work losses and cumulatively rising conflict with supervisors, employers and the state. None of these can be expected to enhance the prospects for successful stabilisation. however defined.
}

It would be inaccurate to say that the IMF is totally impervious to SSA realities. It does in specific cases recognise the problem of fitting its time frame to that needed to achieve results in some SSA economies. It does see barriers to rapid import liberalisation and to cutting imports below current levels (indeed several programmes - either actual or under negotiation specify raising import levels as a key objective). It does not uniformly advocate trade surpluses as a viable short term target [but see Bhatia and Tahari, 1984]. But these appear to be ad hoc adjustments in specific cases and are not based on any general reappraisal or critique of the underlying assumptions of the Fund's approach to stabilisation.

\section{Non-Questions and Questions -}

Querying the IMF model does not imply asserting that one can avoid adjustment; that domestic policy played no role in causing or exacerbating imbalances; that prices do not matter; nor that additional access to foreign exchange without coherent domestic strategies can be a sufficient condition for stabilisation, rehabilitation and recovery. Resource use must, by one means or another, be adjusted to resource availability. Domestic policy has caused some situations of imbalance and worsened most. Delayed response to the 1979 crisis (based in many caes on the not then unreasonable view that the world economy in 1979-83 would resemble 1974-78) has greatly heightened problems both of stabilisation and structural adjustment. Getting the prices wrong is a credo with few adherents and, if anything, most SSA governments now place more weight on getting nominal prices right than this as a single instrument can bear. Coherent and sustained strategies related to actual structures and possibilities are necessary for additional access to resources to have sustained positive results (as the Sudan, Zaire and Zambia cases demonstrate graphically). ${ }^{7}$

However, a series of questions does flow from comparison of the model's assumptions and existing scenarios and structures in SSA:

If stabilisation is required basically because of falls on the supply side, should structural adjustment not focus on restoring command over resources, particularly by higher capacity utilisation, enhanced maintenance/rehabilitation, expansion of import earning capacity (i.e. exports) and critical import saving capacity (i.e. import substitution) rather than on further cuts in demand? The view that some

\footnotetext{
7 All three have embarked on - if not sustained - numerous externally designed and funded stabilisation and recovery strategies. Equally each is among the relatively few large SSA economies whose gross inflows of aid, IMF funds and nonconcessional finance in real per capita terms are apparently markedly higher in the early 1980s than a decade ago.
} 
austerity programmes which centre on demand cuts provide inadequate stimulation for export employment and growth (i.e. structural adjustment) is widely held [AED 1985].

Given rigidities in economic structures and poor prospects for currently dominant exports, should export promotion and import substitution be seen as alternatives, or opposite sides of the same coin in restoring external balance in a manner consistent with resumed expansion of output?

In the light of numerous real constraints - physical, personnel, institutional - can a rehabilitation strategy best be built down from a macro-monetary policy pattern or up from a set of real, sectoral programmes (a question which overlaps with the relative emphasis given to supply expansion/demand curtailment)?

Can a stabilisation strategy succeed (in the sense of enduring) unless it either really does relate to largely self reversing problems or is the first stage in a longer term structural adjustment programme to which its short term stabilisation targets are subordinated?

What time frames and types of finance are appropriate for integrated stabilisation/structural adjustment packages?

\section{- And Some Consequential Technical Criticisms}

The question of time frames has already been raised. However, the timing assumptions apparently underlying IMF programmes raise further questions. IMF trigger clause targets usually assume empirical improvement on monetary and fiscal as well as external balance heads within three months of the submission of a letter of intent. This appears to assume either a very powerful expectations effect (given the prevalence of short-lived programme attempts in SSA, this is somewhat unlikely) or a near absence of lags between fund release and results. In the context of SSA this is rarely plausible. Ordering, producing/dispatching and delivering imports relating to current production and maintenance is likely to take three to five months, use in production another two to four months (longer for agricultural inputs), distribution and sale one to three months more and collection of revenue by government or additional cash flow by enterprises to reduce bank borrowing a further one to three months (longer for profits taxes). This adds up to a total of seven to 15 months, with 12 probably a not untypical distributed lag from fund release to the achievement of substantial results for production and the monetary/fiscal balance.
Phasing and sequencing raises similar issues particularly when physical or real (as opposed to monetary and nominal) constraints exist. For example, if the main purchases peasants wish to make are consumer and construction manufactures, and the key constraints on their producing more are inputs (e.g. seeds, fertilisers, hoes) then until these are more readily available neither incentives for, nor real possibilities (apart from better weather) of enhanced peasant production are feasible, irrespective of what nominal price changes are introduced. If the supply gaps are the result of 20 to 40 per cent of capacity local production rates, because the 20 per cent to 40 per cent of ex-factory cost which represents imports cannot be met (a not atypical set of conditions in larger African economies) then foreign exchange allocations (and a source from which to allocate) for industry may be the logical - and near necessary - first step toward restoring or raising agricultural output.

Similarly, whether it is more effective to phase in (ratchet) relative price changes (of foreign exchange or grower prices or electricity or fuel or staple food or wages) depends to a large extent on what the results of rapid changes would be in terms of dislocation and of generating forces which reversed the initial changes. Because many SSA economies are very weak, 'shock' cures may be beyond their capacity to withstand, while the lags between, e.g. nominal changes in grower prices and more goods for growers to buy, may be so long as to cause inflation, which would reverse the relative price incentive before production could respond.

Selectivity - especially in resource cuts - is an area in which the IMF cannot be accused of monolithic consistency. It argues first, at a general level, that one cut is as good as another, second, that cuts should be ranked according to their efficiency at reducing external imbalance, and third, that consumption subsidies, wage earner consumption, production subsidies, general government expenditure and enterprise fixed investment stand in that order as targets.

There is much to be said against excessive wages and large recurrent budget deficits, but it is by no means generally true in SSA that they have a high import (or potential export) content. Nor is it evident that cutting them would reduce credit and inflationary pressures more effectively than cutting profits and investment (Rhodesian experience wotld suggest the reverse). Further, in much of SSA diversion of imports from additional, unselective capacity increases - which will be largely inoperable because of import strangulation - to operating, maintenance and rehabilitation inputs directed to existing capacity would appear to be a priority for stabilisation and 




Lack of capital forces capacity underutilisation.

consolidation of exports and government financial balance, as well as of production and per capita consumption.

Similarly, the presence of foreign balance constraints which, even if stabilised by short run output reduction, pose medium term barriers to future output recovery across the board (including purely price determined), making cutbacks in foreign exchange use, is open to question. Translating Bentham's utilitarian 'pushpin is as good as poetry' into 'brandy, Mercedes and foreign travel costs are as good as hoes, dyestuffs for textiles and staple foods' does not make sense if production or exports are to be enhanced. There is increasing consensus that African economies are too import and too little export intensive and thus no clear efficiency presumption exists against allocation or market intervention to direct foreign exchange and/or domestic credit toward activities likely to raise exports and substitute for critical imports. The absence or inadequacy of these is forcing general underutilisation of capacity.
The appropriate volume, timing and conditions of external resource flows to achieve stabilisation with adjustment allowing return to growth is not one on which the IMF appears to have done systematic analysis. These questions become more urgent the longer the lags before production from present capacity can respond; the greater the time and cost dimensions of structural adjustment; the poorer (or more distant) the export prospects; the lower the real GDP per capita; and the more it has fallen from past peak levels. The answers would seem to include high sectoral programme oriented, long term, low interest finance for a majority of SSA countries - say $\$ 15-30$ per capita additional resources per year for five years to carry out stabilisation and st ructural adjustment. If that is the case - and the World Bank's prudent debt management component of Structural Adjustment Programmes (SAPs?) for low income countries does encompass these assumptions - then except for the most robust, net export earning, quick payoff projects, substantial loans at nine per cent over six years - or even 10 years - will only worsen the medium 
problems. To be only mildly whimsical, the Bank should at the least complement its precondition that a SAP candidate negotiate a Higher Credit Tranche programme with the Fund with the precondition for a low or lower middle income candidate that it must not draw on it.

\section{Tentative Conclusions and Implications}

First, because the IMF model's assumptions are inconsistent with the actual circumstances of almost all SSA countries, stabilisation programmes built on them are likely to be to some degree inappropriate

Second, this may not matter in cases where the country in question launches stabilisation rapidly with the advantages of i) recent rises in imports, personal consumption and government expenditure as well as reserves or lines of credit; and ii) an improvement in the external economic environment within a year or 18 months. In these cases, of which Botswana is an example, quite different assumptions from the IMF's might well lead to the same programme.

Third, in other cases an IMF type stabilisation programme is likely to be incomplete, inadequate and - less certainly - partly in the wrong direction. Its weaknesses are likely to lie in underest imating - or in extreme cases overlooking - the importance of real, sectoral or micro, versus monetary, macro factors; in placing too little emphasis on supply rebuilding versus demand constraint; in overest imating the efficiency of unselective market forces from the point of view of a recovery in production or the external balance and in underestimating both the time period needed for stabilisation and structural adjustment, and the need to view stabilisation primarily as a part of structural adjustment, not an end which can be attained by itself.

Fourth, incompleteness and/or inadequacy has significant costs. These include: substantial delays in negotiating programmes; a high probability of programme collapse; a tendency for debate (not least by critics of the IMF) to concentrate on the IMF's agenda so that other equally critical questions remain unexplored and unanalysed (to the detriment of alternatives) and, in some cases, a rigidity in reaction to the IMF which slows or blocks genuine stabilisation measures. ${ }^{8}$

Fifth, even if the IMF's broad stabilisation policies are appropriate as the first steps toward structural

\footnotetext{
8 e.g. in Tanzania exchange rate adjustment has been lagged by about one year and lumpier (i.e. fewer, longer changes) than if there had been no dialogue with the Fund and analysis of its complex impact on sustainable export crop prices, production subsidy burdens on the budget, income distribution and their interaction has been hampered by any such work being categorised more as pro or anti IMF than as probably broadly correct or of doubtful accuracy.
}

adjustment, six year-nine per cent funding is clearly inappropriate for low and most lower middle income countries

\section{References}

Africa Economic Digest (AED), 12 April 1985:3

Bhatia, R. J. and A. Tahari, 1984, 'External debt management and macroeconomic variables: problems of African countries' in External Debt Problems of African Countries in the 1980s, African Centre for Monetary Studies, Dakar

Dell, S., R. Lawrence and G. K. Helleiner, 1985, '1973-90 Developing Country Adjustment Study', Special Issue, World Development

Green, R. H. (ed), 1985, 'Sub-Saharan Africa: toward oblivion or reconstruction?', Journal of Development Planning no 15, United Nations, New York

Helleiner, G. K., 1984, 'Outward orientation, import instability and African economic growth: an empirical investigation' (mimeo - to appear in Festschrift in honour of Paul Streeten)

- 1985, 'Aid and liquidity: the neglect of SSA and others of the poorest in the emerging international monetary system' in Journal of Development Planning no 15

Institute of Development Studies, 1983, 'Accelerated Development in sub-Saharan Africa: What Agendas for Action?' (eds C. Altison and R. H. Green), IDS Bulletin vol 14 no 1

Kadhani, X. and R. H. Green, 1985, 'Parameters as warnings and guideposts: the case of Zimbabwe' in $J D P$ no 15

- 1984, The IMF and Stabilisation: Developing Country Experience, Heinemann, London

Killick, T., 1984, The IMF and Stabilisation: Developing Country Experience, Heinemann, London

-(ed), 1984, 'The IMF's role in developing countries', Finance and Development, September

de Larosiere, J., 1984, Does The Fund Impose Austerity?, IMF, Washington DC

Loxley, J., 1984, 'IMF and World Bank conditionality and sub-Saharan Africa', Papers and Proceedings, 1984 African Studies Association (USA) Conference, (microfiche)

Rwegasira, D., 1984, 'Exchange rates and the management of the external sector in sub-Saharan Africa', (mimeo forthcoming in Journal of Modern African Studies)

Williamson, J., 1982, The Lending Policies of the International Monetary Fund, Institute for International Economics, Policy Analyses in International Economics No. 1, August - 1984, IMF Conditionality, IIE, Washington DC

World Bank, 1981, Accelerated Development in sub-Saharan Africa: an Agenda for Action, Washington DC

- 1984, Toward Sustained Development in sub-Saharan Africa: a Joint Programme of Action, Washington DC 